regarding the method of financial support, the most favoured being the establishment of a Museum and Art Gallery Grants Board on the lines of the University Grants Committee. The Board would consist of experts sympathetic with museum and art gallery problems, and these would "assess schemes, allocate grants, and impose conditions which, under a scheme of inspection, would ensure the maintenance of suitable standards, and so assist in raising the status of museums and art galleries throughout the country".

Museums and art galleries form cultural centres : they educate, and provide for the intelligent use of leisure; they are in contact with a very wide public, and are, therefore, in a particularly favourable position for the diffusion of knowledge based on scientific principles: they have (or should have), therefore, a very definite place within any intelligent community. In this light, the direct appeal for government support and encouragement which this document puts forward is worthy of the closest consideration.

\section{WAVE-LENGTHS FOR EUROPEAN BROADCASTING}

$\mathrm{T}$ HE wave-lengths or frequencies used by broadcasting stations in Europe in normal times were the result of discussions and conferences held under the auspices of the International Broadcasting Union formed about twenty years ago. It was as a result of the activities of this Union that the Lucerne plan was formulated and put into practical operation during the night of January 14-15, 1934, when a general re-distribution of wave-lengths of European broadcasting stations was conducted by the responsible organizations. In April 1939 a revised plan was drawn up in the form of the Montreux Convention, which was signed by the representatives of thirty-one States; and this plan provided for certain changes in wave-length and power of European broadcasting stations to come into effect in March 1940. Although the operation of this plan was in any case prevented by the War, it is doubtful whether it would have been successful had it been applied; for, as Sir Noel Ashbridge remarked in his presidential address to the Institution of Electrical Engineers in 1941, these international conferences were rendered very difficult by the various political influences involved. Sir Noel expressed the hope that, after the War, it would be possible for a well-based wave-length plan for Europe to be built up on rational principles with due regard. to technical facts.

It is with the view of rendering assistance towards this objective that the Radio Industry Council has recently issued a report entitled "Post-War European Broadcasting", prepared by the technical committee of the British Radio Equipment Manufacturers' Association (Radio Industry Council, 59 Russell Square, London, W.C.1). This report outlines a new proposal, based upon technical considerations and on appreciation of the ordinary listener's requirements, for the allocation of wave-lengths among the thirty European countries. The proposal aims at providing for every nation at least one, and in most cases two, programmes which adequately cover the entire country ; in addition, a system of regional programmes would be provided to meet local requirements, and in particular the major language groups in each country. The whole scheme would also provide for every listener good signals from some foreign stations in addition to his own national and regional programmes.

For the plan to be successful in attaining these objectives, it is clearly necessary to arrange wavelengths in relation to the location and power of the transmitters, so as to minimize interference between any two stations, and to permit reasonable quality of reproduction from receivers in all parts of the service area of each station. Power as well as wave-length would have to be specified in order to ensure good service over each area, while still avoiding serious interference with other transmitters.

As a basis for the proposals put forward in the report, the radius of the service area or coverage of a broadcasting station is defined as the distance to which the ground-wave signal is greater than 2 $\mathrm{mV}$./metre, and the ionospheric or sky-wave signal which causes fading is never more than a certain value to be selected on the basis of experience. Based upon such assumptions, the report states that the primary service area of medium-wave broadcasting stations is a circle, the radius of which in miles is approximately equal to one-quarter of the wave-length in metres. Proceeding along these lines, the main national allocations are obtained by using the whole of the existing long-wave broadcasting band of 156-288 ke./s. (wave-lengths 1,040-1,920 m.) together with the extension envisaged in the Montreux plan of $344_{\mathrm{T}} 432 \mathrm{kc} / \mathrm{s}$. $(695-873 \mathrm{~m}$.$) . In this extended$ long wave-band, sufficient frequency allocations are proposed, at intervals of $11 \mathrm{kc} . / \mathrm{s}$. between stations, to provide two national programme services for each of the thirteen larger countries; European Russia being regarded as two countries as it has two main languages. For the seventeen smaller countries the size of which does not require the use of long waves to secure effective coverage, the national programmes are allocated to some, but not the whole, of the band between $552 \mathrm{kc} / \mathrm{s}$. and $1,157 \mathrm{kc} . / \mathrm{s}$. $(260-544 \mathrm{~m}$.). The remainder of the medium wave-band, up to $1,553 \mathrm{kc} . / \mathrm{s}$. (193 m.), with one or two exceptions, and the portions of the above band not used for national services, are to be divided up for regional purposes, common-wave working being envisaged for stations separated by a distance of at least 1,500 miles. The scheme suggests provision for eleven regional transmitters in Great Britain and Northern Ireland in addition to two national transmitters working on $178 \mathrm{kc} . / \mathrm{s}$. $(1,685 \mathrm{~m}$.) and $222 \mathrm{kc} . / \mathrm{s}$. (1,350 m.).

In brief, the proposed plan claims to give the following facilities: two adequate national channels for every country; an increase in the frequency separa. tion from $9 \mathrm{kc} . / \mathrm{s}$. to $11 \mathrm{kc} . / \mathrm{s}$., resulting in a material decrease in interference ; and a better regional service even in England, and vastly better for the majority of Europe. If the complete scheme is to be satisfactory, however, it is emphasized that it is essential 


\section{No. 3957 September I, $1945 \quad$ N A T U RE}

to have better control and regulation of the power, frequency and modulation of broadcasting transmitters all over Europe than has been the case in the past.

In presenting the report summarized above, the Radio Industry Council makes it clear that its proposed solution of the problem is by no means rigid or final, since considerable elasticity is offered in the exact wave-length allocations without affecting the general scheme. It is, however, commended to the earnest consideration of those who are able to influence the future development of broadcasting, in the belief that the present phase in Europe presents a valuable opportunity and, in the view of the British radio engineers represented by the above Council, an obligation to correct past mistakes.

\section{SYNTHETIC RUBBER FROM ALCOHOL}

\section{Synthetic Rubber from Alcohol}

A Survey Based on the Russian Literature. By Anselm Talalay and Michael Magat. Pp. xiii +298 . (New York: Interscience Publishers, Inc., 1945.) 5 dollars.

$\mathrm{T}$ HIS book is well written and printed, free from typographical mistakes, and generally very readable. It is divided into four chapters. The first chapter deals with the chemistry of the Lebedev process for preparing butadiene from alcohol, the second with the technology of the process, the third with the fundamentals of polymerization, including a sub-section on the technology of sodium polymerization, and the fourth with the physico-chemical properties of the polymer, including a most important section on determining the structure of the polymer. While the book as a whole was a co-operative effort of both authors, Chapters 1 and 2 were mainly the responsibility of $\mathrm{A}$. Talalay and Chapters 3 and 4 of M. Magat. It is to be regretted that a further chapter dealing with Russian experience in handling polybutadiene in the rubber factory was not added. Useful author and subject indexes are appended.

The writing of the book is justified by the fact that so few English-speaking technical men ean read Russian. A survey must always suffer from lack of authoritative information, and this book is no exception. While the authors have done a good piece of work in bringing together so much valuable information locked away in journals difficult to obtain and more difficult to translate, the reader has the impression that the authors are no better informed on what real progress has been made in the development of synthetic rubber in the U.S.S.R. than he is himself.

This doubt arising from the reviewing of the work of others is quite frankly expressed in the text by the use of the word 'apparently'. This is really a great virtue on the part of the authors, since less honest writers might have been tempted to identify their own views with those of the original authorities.

It is also regrettable that Russian references to more recent work (most of the references are more than ten years old) are not very numerous.

Attention should be directed to the statement on p. 145: "the Germans soon abandoned this method of polymerisation" [sodium polymerization]. This is, of course, untrue since the Germans only abandoned it for the production of products which could be made more efficiently by the dispersion technique. Conversely, more attention could have been paid to the reasons why emulsion polymerization offered difficulties in the case of straight butadiene polymerization.

The practical side of the book (that is, the technology of production) deals almost exclusively with the production of butadiene and polybutadiene. This, naturally, is to be expected from the second part of the title of the book. The reviewer is somewhat surprised that the authors have not mentioned in their introduction Smirnov's book, which covers largely the same ground, at least from the technological angle. It is also rather to be regretted that the title (save for the second conditional part) and contents may lead beginners in the field to the wrong conclusion that polybutadiene is the most important rubber produced from alcohol. Buna $S$ (or its analogues) is, of course, the most important synthetic rubber produced from alcohol in the past and present, although there are some indications that polybutadiene may be the most important in the future. This possible misunderstanding might have been avoided by employing a more limited title such as "Polybutadiene Rubber from Alcohol". The authors have, indeed, pointed out that the copolymers with styrene and acrylonitrile are important, but, in the view of the reviewer, with insufficient emphasis. It is true that some specific information regarding the American processes is still restricted, but no one could deny that far more has been published regarding the general position of synthetic rubber development in the United States than in the U.S.S.R.

A considerable amount of the material contained in the theoretical sections of the book is derived from non-Russian sources, and this makes it even more regrettable that more attention was not given to the production of Buna types from alcohol in the early technological sections of the book. A correspondingly large proportion of non-Russian references in the early part of the book would have made this possible.

The book is essentially one for the chemist interested in the development of synthetic rubber. It is feared that the average rubber technologist will find the treatment of the subject too academic. On the whole it is a book to be recommended.

W. J. S. NAUNTON.

\section{PRACTICE AND SCIENCE IN THE SHEEP INDUSTRY}

\section{(I) The Merino}

Past, Present and Probable. By H. B. Austin. Second edition. Pp. 247. (Sydney: Grahame Book Co., 1944.) n.p.

(2) Sheep

By J. F. H. Thomas. With Chapters by Moses Griffiths, Martin Jones and A. R. Wannop. Pp. $196+$ 44 plates. (London: Faber and Faber, Ltd., 1945.) 15s. net.

"THE sheep has golden hooves, and wherever the print of them appears, the soil turns to gold." This old Swedish proverb is quoted by Mr. Austin ; Mr. Thomas could equally well have taken it for one 